\title{
The Proportion Of Lung Hyperinflation In Patients With Persistent Asthma In Persahabatan Hospital Jakarta Using Multiple Breath $\mathbf{N}_{2}$-Washout
}

\author{
Marisa Afifudin, Faisal Yunus, Triya Damayanti \\ Department of Pulmonology and Respiration Medicine, Faculty of Medicine, Universitas Indonesia - \\ Persahabatan Hospital, Jakarta
}

\begin{abstract}
Background: In asthma, small airway dysfunction and inflammation may induce significant lung hyperinflation. The aim of the study is to discover the proportion of lung hyperinflation in patient with persistent asthma in Persahabatan Hospital Jakarta.

Method: A cross sectional study with descriptive analysis was done in Asthma clinic Persahabatan Hospital from September-November 2016. Forty-five subjects were recruited consecutively. Interview, physical examination, chest x-ray (CXR), spirometry and multiple breath $\mathrm{N}_{2}$-washout (MBW) were performed. Lung hyperinflation was defined as a residual volume /total lung capacity (RV/TLC\%) above the upper limit of normal.
\end{abstract}

Results: The proportion of lung hyperinflation in patients with persistent asthma was 17,8\% (8 of 45 subjects). Median RV in milliliter was 1230 (570-2860). Median functional residual capacity (FRC) in milliliter was 1730 (970-3990). Median TLC in milliliter was 3310 (24906350). Mean RV/TLC ratio was $36.39 \%$ ( $S D \pm 8.86$ ). Mean $F R C / T L C$ ratio was $52.86 \%$ $(\mathrm{SD} \pm 6.85)$. There was a significant correlation between forced expiratory volume in 1 second $\left(\mathrm{FEV}_{1} \%\right)$ value with lung hyperinflation with the decline of $\mathrm{FEV}_{1}<60 \%$ increased the risk of lung hyperinflation by $8,46(95 \% \mathrm{CI}=1.155-61.98 ; \mathrm{P}=0.036)$. There were no significant correlation between age, gender, smoking habit, body mass index (BMI), ACT score, the severity of persistent asthma, duration of asthma, duration of steroid inhalation use, exacerbation history in the last 12-months and emphysematous in CXR with lung hyperinflation $(P>0.05)$.

Conclusion: The proportion of lung hyperinflation in patient with persistent asthma in Persahabatan Hospital Jakarta is $17,8 \%$. Lung hyperinflation in persistent asthma is associated with the degree of airway obstruction.

Keywords: lung hyperinflation, persistent asthma, multiple breath $\mathrm{N}_{2}$-washout

*Correspondence: Triya Damayanti - tria_94@yahoo.com

Submitted: February 14 $4^{\text {th }}$ 2021, Accepted: February 27h 2021, Published: February $28^{\text {th }} 2021$ 


\section{INTRODUCTION}

Asthma is a disease characterized by an increase in airway reactivity. Patients with asthma have persistent or recurrent airflow obstruction, either reversible or spontaneously. The number of asthma patients around the world will increase by estimated 100 million in 2025. The cause of mortality due to asthma every year is estimated 250,000 people. ${ }^{1}$

At the household health survey, asthma, chronic bronchitis and emphysema as fourth or $5.6 \%$ cause of death (mortality) in Indonesia. In 1995, the prevalence of asthma throughout Indonesia amounting 13/1000, compared to chronic bronchitis $11 / 1000$ and pulmonary obstruction 2/1000.2

Obstructive pattern is the most common pattern, identified through the decline of forced expiratory volume in 1-second $\left(\mathrm{FEV}_{1}\right)$ and $\mathrm{FEV}_{1}$ ratio with forced vital capacity $\left(F E V_{1} / F V C\right)$ or $\mathrm{FEV}_{1} /$ vital capacity (VC). Some patients may have a decreasing FVC from air trapping, result in pseudophysiologic emphysema in lung function test with increasing total lung capacity (TLC), functional residual capacity (FRC) and residual volume (RV). ${ }^{3}$

The present physiologic study evaluated patients with moderate to severe, chronic persistent asthma who have seemingly irreversible lung function despite aggressive treatment, to determine the mechanisms of airflow limitation. Physiologic consequences of loss of lung elastic recoil in chronic persistent asthma include hyperinflation, premature airway closure, and abnormal expiratory airflow. ${ }^{4}$ It is widely known that patient with asthma chronic may develop some degree of hyperinflation which may persist after remission. ${ }^{5}$

Lung hyperinflation is probably one of the major causes of dyspnea in patients with asthma. Hyperinflation is a compensated mechanism as a response of the airway resistance. In routine clinical practice, hyperinflation is usually defined by an FRC above $120 \%$ of predicted, which is generally preceded by an elevation in RV and thus an increase in the ratio of RV to the TLC (RV/TLC). ${ }^{4-6}$

Study of lung hyperinflation in asthma patient in Indonesia had not been done yet, thus the authors aimed to discover the event of lung 
hyperinflation in patient with persistent asthma. Lung function tests to determine lung hyperinflation can be done using body plethysmograph, gas dilution and washout. A nitrogen washout procedure can be performed with a single nitrogen breath washout (SBW) or multiple breath $\mathrm{N}_{2}$ washout (MBW). MBW requires only passive cooperation and minimal coordination. In this study we were using MBW procedure.

The aim this study to discover the proportion of lung hyperinflation in patient with persistent asthma in Persahabatan Hospital Jakarta using multiple breath $\mathrm{N}_{2}$-washout.

\section{METHOD}

A cross sectional study were done in Department of Pulmonology and Respiratory Medicine - Persahabatan Hospital Jakarta during SeptemberNovember 2016. Inclusion criteria including patient diagnosed with persistent asthma based on medical record in Asthma Clinic Persahabatan Hospital Jakarta and willing to participate in the study. Exclusion criteria including patient with acute exacerbation or history of exacerbation four weeks prior accompanied by doctor visit, pregnancy, comorbidity such as active tuberculosis (TB) and history of TB, bronchiectasis, interstitial lung disease and malignancy, patient with life threatening infection, other fatal terminal disease and severe comorbid, lung parenchymal abnormality in CXR aside from emphysema and refused to participate.

Subjects were recruited consecutively. Interview, physical examination and vital signs were done in subjects who met the inclusion criteria. Afterwards, CXR were taken in subjects without CXR in the last onemonth. Spirometry and MBW were perfomed using NDD EasyOne ProßLAB. Washout was considered complete if $\mathrm{N}_{2}$ concentration less than $2 \%$ in at least three consecutive breath. At least one measurement was technically acceptable.

$\mathrm{FEV}_{1}, \mathrm{VC}$ and IC determined from spirometry result. FRC measurement done using MBW method. TLC value result from $\mathrm{FRC}+\mathrm{IC}$, then $\mathrm{RV}$ measurement taken from TLC minus VC. Hyperinflation was determined based on RV/TLC above the upper limit of normal. Data were analyzed using 
Statistical Package for Social Science (SPSS) 21.

\section{RESULT}

We interviewed 72 subjects who meet with inclusion criteria. Forty-five subjects completed the study, while 11 subjects had exacerbation just before conducting lung function tests, 4 subjects with severe comorbidity were excluded (3 heart failures, 1 cirrhosis), 3 subjects with parenchymal abnormality aside from emphysema in CXR were also excluded (TB, bronchiectasis, lung edema) and 9 subjects were loss to follow-up.

Table 1. Demography characteristics

\begin{tabular}{llcc}
\hline \multicolumn{2}{c}{ Characteristics } & n & \% \\
\hline Gender & Male & 9 & 20 \\
& Female & 36 & 80 \\
Age (years) & Mean & 50,38 & SD $\pm 14,96$ \\
& $<40$ & 10 & 22,2 \\
& $40-60$ & 22 & 48,9 \\
Smoking & $>60$ & 13 & 28,9 \\
habit & NonSmoker & 38 & 84,4 \\
& Ex-smoker & 7 & 15,6 \\
& Mild BI & 0 & 0,0 \\
\hline
\end{tabular}

Forty-five subjects including 9 males (20\%) and 36 females (80\%) were recruited. Mean age was 50,38 $(S D \pm 14,96)$. Subjects in age group 4060 years old were dominant with 22 $(48,9 \%)$. Seven subjects $(15,6 \%)$ were ex-smokers with mild Brinkman index (BI), while 38 subjects $(84,4 \%)$ were nonsmoker. There was no active

smoker in our study. Demography characteristics as seen in Table 1.

Mean duration of asthma was 21,91 years $(S D \pm 16,45)$ with duration of asthma $>20$ years in 22 subjects (48,9\%). Moderate persistent asthma was dominant group with 36 subjects $(80,0 \%)$. Dominant BMI was obese I with 18 subjects (40,0\%). Median ACT score was 20. Exacerbation in the last 12 -months in 24 subjects $(53,3 \%)$ while $21(46,7 \%)$ subjects with no exaserbation history. Duration of steroid inhalation use $<5$ years was dominant with 26 subjects $(57,8 \%)$. Emphysematous in CXR found in 6 subjects $(13,3 \%)$ (Table 2$)$.

Median FRC (in milliliter) was 1730 (970-3990). Median RV (in milliliter) was 1230 (570-2860). Median TLC (in milliliter) was 3310 (24906350). The complete spirometry and MBW results in Table 3.

Table 3. Spirometry and MBW test results

\begin{tabular}{lcc}
\hline \multicolumn{1}{c}{ Category } & $\begin{array}{c}\text { Mean/ } \\
\text { Median }\end{array}$ & Range \\
\hline FEV $_{1}(\mathrm{ml})$ & 1443,78 & SD $\pm 437,41$ \\
$\mathrm{FEV}_{1}(\%)$ & 75,02 & $\mathrm{SD} \pm 23,62$ \\
Air trapping (\%)* & 5,00 & $0-20$ \\
FRC (ml)* & 1730 & $970-3990$ \\
RV (ml)* & 1230 & $570-2860$ \\
TLC (ml)* & 3310 & $2490-6350$ \\
RV/TLC (\%) & 36,39 & SD $\pm 8,86$ \\
FRC/TLC (\%) & 52,86 & SD $\pm 6,85$ \\
\hline distribution not normal &
\end{tabular}


Table 2. Clinical characteristics

\begin{tabular}{llcc}
\hline \multicolumn{2}{c}{ Characteristics } & $\mathbf{N}$ & $\mathbf{\%}$ \\
\hline Duration of asthma (years) & Mean & 21,91 & SD $\pm 16,45$ \\
& $<10$ & 13 & 28,9 \\
& $10-20$ & 8 & 17,8 \\
Severity of persistent asthma & $>20$ & 24 & 53,3 \\
& Mild & 7 & 15,6 \\
& Moderate & 36 & 80,0 \\
BMI & Severe & 2 & 4,4 \\
& Underweight & 2 & 4,4 \\
& Normal & 9 & 20,0 \\
& Overweight & 8 & 17,8 \\
ACT score & Obesity I & 18 & 40,0 \\
& Obesity II & 8 & 17,8 \\
& Mean & 203 & $6-25$ \\
Exacerbation history (last 12-months) & 25 & 20 & 6,7 \\
Duration of steroid inhalation & $20-24$ & 22 & 44,4 \\
& $\leq 19$ & & 48,9 \\
CXR & Yes & 24 & 53,3 \\
& No & 21 & 46,7 \\
& $<5$ years & 26 & 57,8 \\
& $\geq 5$ years & 19 & 42,2 \\
& Emphysematous & 6 & 13,3 \\
& No emphysematous & 39 & 86,7 \\
\hline
\end{tabular}

Table 4. Correlation between demography characteristics with lung hyperinflation

\begin{tabular}{lccc}
\hline \multicolumn{1}{c}{ Characteristics } & Hyperinflation & No hyperinflation & P \\
\hline Age & 6 & 15 & $0,083^{*}$ \\
$\leq 50$ & 2 & 22 & \\
$>50$ & & & $0,039^{*}$ \\
Gender & 4 & 5 & \\
$\quad$ Male & 4 & 32 & $0,0637^{*}$ \\
$\quad$ Female & & 6 & \\
Smoking habit & 1 & 31 & \\
$\quad$ Non-smoker & 7 & & \\
Ex-smoker & & &
\end{tabular}

Lung hyperinflation was determined based on RV/TLC above the upper limit of normal ( $R V / T L C>$ pred $+1,64$ residual standard deviation/RSD). Reference value of RV/TLC in adult male $14,0+0,39 \times A$ with RSD 5,46, whilst in adult female 19,0+0,34xA with RSD 5,83 (A: usia).
Reference value of RV/TLC in children and adolescent $21,7(\mathrm{RSD}=5,7){ }^{26,36,37}$ Lung hyperinflation was found in 8 $(17,8 \%)$ patients.

Proportions in persistent asthma for hyperinflation group are $17,80 \%$ meanwhile no hyperinflation group are $82,20 \%$. 
Table 5. Correlation between clinical characteristics, CXR and FEV 1 with lung hyperinflation

\begin{tabular}{|c|c|c|c|}
\hline Characteristics & Hyperinflation & No hyperinflation & $\mathbf{P}$ \\
\hline \multicolumn{4}{|l|}{ Severity of persistent asthma } \\
\hline Mild & 1 & 6 & $0,637 *$ \\
\hline Moderate-severe & 7 & 31 & \\
\hline \multicolumn{4}{|l|}{ ACT score } \\
\hline$<20$ & 6 & 16 & $0,107 *$ \\
\hline$\geq 20$ & 2 & 21 & \\
\hline \multicolumn{4}{|l|}{ Duration of asthma } \\
\hline$<20$ years & 1 & 18 & $0,065^{*}$ \\
\hline$\geq 20$ years & 7 & 19 & \\
\hline \multicolumn{4}{|l|}{ Duration of steroid inhalation } \\
\hline$<5$ years & 6 & 20 & $0,248^{*}$ \\
\hline$\geq 5$ years & 2 & 17 & \\
\hline \multicolumn{4}{|l|}{ Exacerbation last 12 -months } \\
\hline Yes & 5 & 19 & $0,431^{*}$ \\
\hline No & 3 & 18 & \\
\hline \multicolumn{4}{|l|}{ BMI } \\
\hline Underweight-normal & 3 & 8 & $0,298 *$ \\
\hline Risk & 5 & 29 & \\
\hline \multicolumn{4}{|l|}{ CXR } \\
\hline Emphysematous & 1 & 5 & $0,714 *$ \\
\hline No emphysematous & 7 & 32 & \\
\hline \multicolumn{4}{|l|}{$\mathrm{FEV}_{1}$} \\
\hline$\geq 60 \%$ & 3 & 30 & $0,022 *$ \\
\hline$<60 \%$ & 5 & 7 & \\
\hline
\end{tabular}

*Fisher test

Table 6. Multivariate logistic regression analysis

\begin{tabular}{lccc}
\hline \multicolumn{1}{c}{ Variable } & OR & $\mathbf{9 5 \%}$ CI & P \\
\hline ACT $<20$ & 7,87 & $0,74-52,63$ & 0,088 \\
Male & 6,99 & $0,93-83,33$ & 0,059 \\
Steroid use $<5$ years & 8,06 & $0,71-90,90$ & 0,092 \\
Decrease of FEV $_{1}<60 \%$ & 8,46 & $1,155-61,98$ & 0,036 \\
\hline
\end{tabular}

Tabel 4 shows demography characteristics of age, gender and smoking habit with lung hyperinflation. The bivariate analysis shows a significant correlation between gender and lung hyperinflation $(P=0,039)$, nevertheless, in multivariate analysis afterwards shows no significant correlation.

Tabel 5 shows the correlation between clinical characteristics, CXR and $\mathrm{FEV}_{1}$ with lung hyperinflation. In bivariate analysis, there was a significant correlation between $\mathrm{FEV}_{1}(\%)$ and lung hyperinflation $(P=0,022)$ with $5(41,7 \%)$ subjects 
had decline of $\mathrm{FEV}_{1}<60 \%$. There were no significant correlation between BMI, ACT score, the severity of persistent asthma, duration of asthma, duration of steroid inhalation use, exacerbation history in the last 12 months and emphysematous in CXR with lung hyperinflation.

Afterwards, lung hyperinflation associated with age, gender, ACT score, duration of steroid inhalation use, duration of asthma and $\mathrm{FEV}_{1}$ $(P<0,25)$ were analyzed using backward stepwise logistic regression. There was a significant correlation between FEV1\% value with lung hyperinflation with the decline of $\mathrm{FEV}_{1}$ $<60 \%$ increased the risk of lung hyperinflation by 8,46 in persistent asthma $\quad(95 \% \quad \mathrm{CI}=1.155-61.98$; $\mathrm{P}=0.036$ ). Table 6 shows the multivariate analysis between the variables.

\section{DISCUSSION}

Present results show that approximately $50 \%$ of patients with poorly controlled asthma or baseline dyspnea exhibit a significant resting hyperinflation and patients with hyperinflation had lower $\mathrm{FEV}_{1}$ and $\mathrm{FEV}_{1} / \mathrm{FVC}$ values, worse asthma control, and a longer history of asthma. These findings confirmed that subjects with chronic asthma often develop some degree of hyperinflation, which may persist in the periods between exacerbations in patients with insufficiently controlled asthma. It is generally accepted (but not definitively proven) that lung hyperinflation is mainly related to abnormalities in the distal airways.

Natsir et al study in Persahabatan Hospital with 31 mild asthma subjects (intermitten and mild persistent) and 29 severe asthma (moderate-severe persistent). ${ }^{7}$ Subjects characteristics were relatively similar in gender dominated by female (mild asthma $90.3 \%$, severe asthma $79.3 \%$ ), nonsmoker (mild asthma 96.8\%, severe asthma 96.6\%), ACT score 1-20 (severe asthma 51.7\%) and last 12months exacerbation history (severe asthma 58.6\%). Characteristics were found different in BMI normal (mild asthma $38.7 \%$, severe asthma $41.4 \%$ ) and the severity of persistent asthma dominated by mild persistent asthma with 24 subjects.

Perez et al evaluated lung hyperinflation in 305 subjects with 287 uncontrolled asthma. Subjects 
characteristics which relatively similar with our study were mean age 48.7 (SD \pm 17 ) years, BMI obese (mean BMI 25.2; $\mathrm{SD} \pm 4.5)$, mean duration of asthma is 18.4 ( $\mathrm{SD} \pm 18,3$ years) and ex-smoker subjects (16.6\%). Different characteristics were found in lower mean ACT score 14.1 (SD \pm 4.1$)$ and active smoker subjects (14.4\%). ${ }^{6}$

Gelb and Zamel studied 18 adults with chronic persistent asthma and one year exacerbation history. Subjects characteristics which relatively similar with our study was mean age 59 (SD \pm 15$)$ years and different with our study in gender, mostly male (12 subjects). ${ }^{4}$ Zwitserloot et al studied 32 children diagnosed with asthma with mean age of 11.3 $(4,717,4)$ and 19 male subjects. Steroid inhalation use in 22 subjects, mean ACT in age group <12 yr (11 subjects) was 25 , whilst group $>12 \mathrm{yr}$ (14 subjects) was 23.5. Classification according to GINA were controlled 14 (40.6\%), partly controlled 13 (40.6\%), uncontrolled $4 \quad(12,5 \%)$ and 2 unknown. ${ }^{8}$

The determination of $\mathrm{FEV}_{1} \%$ value was adjusted with predictive value of Indonesian people according to Indonesia Pneumobile Project 1992 calculation. The RV, FRC and TLC values were not presented in percent predicted because the predicted value adjusted to Indonesian people were not available and MBW tool providing only predicted value of South East Asian in general.

Natsir et al study found mean $\mathrm{FEV}_{1} \%$ in mild asthma was $90,12 \%$ $(S D \pm 15,67)$ and in severe asthma was $56.82 \%$ (SD $\pm 14.35 \%$ ). The $\mathrm{FEV}_{1} \%$ difference with our study can be caused by differences in the distribution of asthma degree. ${ }^{7}$ Perez et al evaluated patients with poor controlled and found mean $\mathrm{FEV}_{1} \%$ $75.8 \%(S D \pm 18.7 \%)$ which was similar to our study. Mean RV/TLC was $44.2 \%$ (SD $\pm 11.2 \%)$ which was relatively higher presumably because the study had bigger sample size and lower ACT score compared to our study. ${ }^{6}$

Gelb and Zamel in Los Angeles, USA and Ontario, Canada studied 18 adults with chronic persistent asthma, fixed expiratory airflow obstruction and one year exacerbation history; 12 men, six women, age $59 \pm 15$ yr divided into 3 age groups and found the decrease of $\mathrm{FEV}_{1} \geq 1$. It $\quad(>35 \%$ predicted value) compared to one year before. The $\mathrm{FEV}_{1}$ value were lower 
than our study presumably because of less subjects and age distribution, whilst FRC, RV and TLC values were higher compared to our study presumably because racial difference and the difference of methods. ${ }^{4}$

Bourdin et al using single breath $\mathrm{N}_{2}$-washout (SBNT) in 24 asthmatics (13 females) of various severity but with normal $\mathrm{FEV}_{1}$ were compared with 24 healthy volunteers (13 females) and studied at steady-state after bronchodilatation which was different from our study. The FEV ${ }_{1}, F R C$, RV and TLC values were higher compared to our study presumably because racial differences, asthma subjects including mild degree and the difference of methods. Zwitserloot et al in study of 32 children diagnosed with asthma found the average $\mathrm{FEV}_{1} /$ prediction was $99.7 \%(S D \pm 14.4 \%) .8,9$

Lung hyperinflation was determined based on RV/TLC above the upper limit of normal (RV/TLC>pred +1.64 RSD). $\quad$ Lung hyperinflation was found in $8(17.8 \%)$ patients. Perez et al evaluated lung hyperinflation in poor controlled asthma $(A C T<20)$. Hyperinflation was defined as either a RV/TLC above the upper limit of normal or a FRC $>120 \%$ predicted. The prevalence of lung hyperinflation observed in 48\% (146 dari 305) patients. ${ }^{6}$ Jain et al in a recent observational study, $51 \%$ of patients with symptomatic or nonsymptomatic persistent asthma treated with a fixed ICS/LABA combination displayed lung hyperinflation. ${ }^{10}$ Labbé et al studied 100 asthma children age 5-16 years old then evaluated hyperinflation based on high RV/TLC $>30 \%$ and RV $>120 \%$ and found 40 (40\%) children with lung hyperinflation. ${ }^{11}$ In 2013, Perez et al also investigated small airway disease in 222 subjects with stable asthma, moderate to severe and found $39 \%$ with lung hyperinflation based on high FRC $>120 \%, \quad R V>120 \% \quad$ and RV/TLC $>$ pred+1.64 RSD. ${ }^{12}$

Dykstra et al evaluated 4774 patients with obstructive lung diseases including 19\% (908) subjects with asthma diagnosis based on history taking. The degree of hyperinflation, as determined by RV/TLC ratio, showed in $3 \%$ of asthma subjects or $0,64 \%$ higher among subjects with obstructive lung diseases. The different results compared with our study was presumed because of the 
subject characteristic differences, Perez et al investigated poor controlled asthma with $\mathrm{ACT}<20$, whereas Dykstra et al with asthma subjects regardless the degree of asthma severity. Another difference may be due to our sample size which were smaller. ${ }^{6,13}$

Backward stepwise logistic regression found that the decrease of $\mathrm{FEV}_{1}<60 \%$ has a strong correlation with the risk of lung hyperinflation in patient with persistent asthma by 8.46 (95\% CI=1.155-61.98; $P=0.036)$. This finding showed that subject with persistent asthma may develop some degree of hyperinflation and may persist in a period between exacerbations, influenced by the severity of airway obstruction. Dykstra et $\mathrm{al}^{7}$ study showed strong correlation between lung hyperinflation based on RV/TLC with the degree of airway obstruction $\left(\mathrm{FEV}_{1} \%\right)$. Perez et al also found strong correlation between $\mathrm{FEV}_{1}$ value (mean $64.9 \% \quad(\mathrm{SD} \pm 17.1)$, $\mathrm{P}<0.0001$ ) with lung hyperinflation based on the incresing level RV/TLC. ${ }^{6}$

There were no significant correlation between age, gender, smoking habit, BMI, ACT score, the severity of persistent asthma, duration of asthma, duration of steroid inhalation use, exacerbation history in the last 12-months and emphysematous in CXR with lung hyperinflation. These findings are similar with Perez et al study in 2013 which found no significant correlation between age, gender, smoking habit, ACT score, duration of steroid inhalation use and exacerbation history in the last 12-months with small airway disease and in 2016 which also found no significant correlation between age, smoking habit, BMI, duration of asthma and exacerbation history with lung hyperinflation. ${ }^{12}$

Subjects were dominated by female because most outpatients in Asthma Clinic Persahabatan Hospital Jakarta are female. The determination of lung hyperinflation based on the increasing value of FRC was not assessed. There is no data of FRC predicted value tailored to the Indonesian people. Predicted value of $\mathrm{RV}$ and TLC for the Indonesian people were not exist as well so these percentage values were not calculated. This study did not use or compare with body plethysmograph which was more often used to measure and assess FRC value and lung hyperinflation. 
Feasibility and overestimate results using body plethysmograph were among consideration.

\section{CONCLUSION}

The proportion of lung hyperinflation in patient with persistent asthma in Persahabatan Hospital Jakarta is $17,8 \%$. Median RV in milliliter is 1230 (570-2860). Median FRC in milliliter is 1730 (970-3990). Median TLC in milliliter is 3310 (2490-6350). Mean RV/TLC ratio is $36,39 \%$ $(\mathrm{SD} \pm 8,86)$. Mean $\mathrm{FRC} / \mathrm{TLC}$ ratio is $52,86 \%(S D \pm 6,85)$. There are no significant correlation between age, gender, smoking habit, BMI, ACT score, the severity of persistent asthma, duration of asthma, duration of steroid inhalation use and exacerbation history in the last 12-months with lung hyperinflation in patient with persistent asthma. There is a significant correlation between $\mathrm{FEV}_{1} \%$ value with lung hyperinflation with the decline of $\mathrm{FEV}_{1}<60 \%$ increased the risk of lung hyperinflation by 8,46 . Lung hyperinflation in persistent asthma is associated with the degree of airway obstruction. There is no significant correlation between emphysematous in CXR with lung hyperinflation in patient with persistent asthma.

Recommendations from researchers are further studies with healthy subjects as control, using other methods such as body plethysmograph, single breath $\mathrm{N}_{2}$-washout and CT scan. Lung function test using multiple breath $\mathrm{N}_{2}$ washout as a routine test is recommended in patient with persistent asthma to assess lung hyperinflation, assist clinical decisions, thus improve hospital service. Further studies on normal value of residual volume, functional residual capacity and total lung volume based on age and height of Indonesian people such as Pneumobile Project 1992 are needed.

\section{REFERENCES}

1. Global Initiative for Asthma. Global Strategy for Asthma Management and Prevention. World Health Organization; 2015.

2. Tim Kelompok Kerja Asma. Asma: Pedoman Diagnosis \& Penatalaksanaan Di Indonesia. Perhimpunan Dokter Paru Indonesia; 2014.

3. Miller A, Palecki A. Restrictive impairment in patients with asthma. Respir Med. 2007;101(2):272-276.

4. Gelb AF, Zamel N. Unsuspected pseudophysiologic emphysema in chronic persistent asthma. Am $\mathrm{J}$ Respir Crit Care Med. 
2000;162(5):1778-1782.

5. Kinsella M, Muller NL, Staples C, Vedal S, Chan-Yeung $M$. Hyperinflation in asthma and emphysema: Assessment by pulmonary function testing and computed tomography. Chest. 1988;94(2):286-289.

6. Perez T, Chanez P, Dusser D, Devillier P. Prevalence and reversibility of lung hyperinflation in adult asthmatics with poorly controlled disease or significant dyspnea. Allergy Eur J Allergy Clin Immunol. 2016;71(1):108-114.

7. Natsir B, Yunus F, Damayanti T. Hubungan antara hasil pemeriksaan kepasitas difusi paru terhadap karbonmonoksida (DLCO) metode napas tunggal dengan derajat keparahan asma pasien di Rumah Sakit Umum Pusat Persahabatan Jakarta. Published online 2016.

8. Zwitserloot A, Fuchs SI, Müller C, Bisdorf K, Gappa M. Clinical application of inert gas Multiple Breath Washout in children and adolescents with asthma. Respir Med. 2014;108(9):1254-1259.

9. Bourdin A, Paganin F, Préfaut $C$, Kieseler D, Godard P, Chanez P.
Nitrogen washout slope in poorly controlled asthma. Allergy Eur $J$ Allergy Clin Immunol. 2006;61(1):85-89.

10. Jain V V., Abejie B, Bashir MH, Tyner T, Vempilly J. Lung volume abnormalities and its correlation to spirometric and demographic variables in adult asthma. $J$ Asthma. 2013;50(6):600-605.

11. Labbé G, Merlin E, Kauffman C, Fauquert JL, Héraud MC, Labbé A. Intérêt de la mesure des volumes pulmonaires par pléthysmographie corporelle dans le suivi de l'asthme de l'enfant. Rev Mal Respir. $2010 ; 27(1): 42-48$.

12. Perez $T$, Chanez $P$, Dusser $D$, Devillier P. Small airway impairment in moderate to severe asthmatics without significant proximal airway obstruction. Respir Med. 2013;107(11):1667-1674.

13. Dykstm BJ, Scanion PD, Rester MM, Beck KC, Enright PL. Lung volumes in 4,774 patients with obstructive lung disease. Chest. 1999;115(1):68-74. 